\title{
ポリビニルアルコール水溶液の電解質による 凝固に関する研究
}

\author{
株式会社クラレ中央研究所中保治郎・川井収治 \\ 網屋繁俊・赤羽健志 \\ 早稲田大学 理工学研究所 浜 義昌
}

\section{COAGULATION OF AQUEOUS POLY(VINYL ALCOHOL) SOLUTIONS BY VARIOUS ELECTROLYTES}

\author{
By Haruo Nakayasu, Yoshimasa Hama*, Shuji Kawai, \\ Shigetoshi Amiya and Takeshi Akahane \\ (Central Research Laboratories, Kuraray Co., Ltd. \\ 2045-1, Aoeyama, Sakazu, Kurashiki 710, Japan) \\ * (Science and Engineering Research Laboratory, \\ Waseda University, 3-4-1, Okubo, Shinjuku-ku, \\ Tokyo 160, Japan)
}

The coagulation of poly(vinyl alcohol) (PVA) solutions under the actions of various electrolytes has been studied.

The quantities of the electrolytes required for the coagulation of the PVA solutions become smaller as the polymerization degree of PVA, the PVA concentration and the temperature become higher. For PVA concentrations lower than a critical value that depends on the polymerization degree, the end point of coagulated gel formation was hard to recognize in the titration of the solution by the electrolyte solution. ${ }^{1} \mathrm{H}$ NMR and dynamic viscoelasticity measurements on the samples before and after coagulation suggest that some degree of the mobility of PVA chain is required for the coagulation and that the mobility is decreased as the coagulation proceeds.

(Received October 27, 1979)

\section{1. 緒言}

ポリビニルアルコール (PVA) の濃厚水溶液を電解質 水溶液で滴定すると，被滴定液は著しく粘皏となり，遂 には襍しょうする。嚾しょうするまでに滴定した塩の量 を用いて凝固倩在表わす方法は，大杉 ${ }^{1)}$ にっって提唱さ れて以来PVAの紡系液の凝固性の評価に広く利用され てきた。

本報では，乙の方法を用いて，PVA 水溶液が電解質 の作用によって疑固する際に，電解質の種類，温度， PVAの重合度および濃度がいかなる影響を及ぼすかに ついて調へた結果について報告する。また電解質による PVA水溶液の凝固に関連するNMRおよび動的粘弾性の 測定結果についても報告する。

\section{2. 試料ならひに実騒方法}

\section{(1) 試 料}

PVAは重合度P：500，1700および33000市骐品を 使用した。溶媒には水扰よび重水を用い，所定澀度にな るようにPVA上混合し加熱して溶解した。電解質はい ずれも市販の試薬を用いた。

\section{(2) 実験方法}

（i）凝固値の測定：PVA水溶液 $20 \mathrm{~g}$ をビーカーにと り，擋拌しながら電解触水溶液を滴定した。PVA水溶 液が離しょうした瞬間に滴定を止め，滴定に要した電解 賈水溶液の体積，又は霆量を测って離しょうするまでに 滴定に要した電解犋の量を求めた。

(ii） NMRの測定：PVAの重水溶液，そのゲル化物 および疑固させた試料を， ${ }^{1} \mathrm{H}-\mathrm{NMR}$ 分光計(バリアン社 
製EM-390)にて室温で測定した。基準物質は添加せす 外部ロックで測定した。

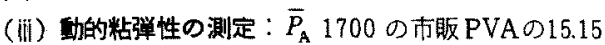
名水溶液 $40 \mathrm{~g}$ 亿漕度 $30.72 \%$ の 芒硝 $\left(\mathrm{Na}_{2} \mathrm{SO}_{4}\right)$ 水溶液 $2.88 \mathrm{cc}$ を均一に添加した。滴定後の試料をすばやく极 じれ振り子型の二重円筒レオメーター2)の cupに入れて bobを取り付け， $10{ }^{\circ} \mathrm{C}$ 亿急冷した。以後適当な時開閏 隔て動的剛性率 $G^{\prime} G^{\prime} G^{\prime}$ を測定して損失コンプライアンス $J ゙$ を計算した。ての操作は 24 時間にわたって続け，次 いでし/分で异温し，㒕しょうするまで $G^{\prime}, G^{\prime}$ を測定し た。

\section{3. 実験結果および考察}

PVA水溶液を $\mathrm{Na}_{2} \mathrm{SO}_{4}$ 水溶液 ゙滴定して疑固値を求 漈の滴定の終点は，離しょう液の少量の分離，全体 か白蜀したゲルの生成，檔拌抵抗の急激な減少，擋拌棒 へのPVA水溶液の付着がなくなるととなどから判定さ れる。

本研究でもPVA水溶液を擋拌しながら $\mathrm{Na}_{2} \mathrm{SO}_{4}$ 水溶 液を滴定した。滴定の進行之ともにPVA 水溶液は透明 度を失うが，その時期は滴定液の $2 \sim 3$ 滴の範囲でとら えうるほど明膫ではなく，また透明度が減少してす離し ょうは起こらない。透明度を失ったPVA 水溶液にさら に滴定をつつける之液は次第に粘䅕度を增し，摚洋の抵 抗も非常に大きくなって遂には滴定液の 1 ２滴の範围 で明膫な離しょうが起こる ${ }^{3)}$ 。通常紡系に用いられるよ うな濃度のPVA水溶液を $\mathrm{Na}_{2} \mathrm{SO}_{4}$ 水溶液で滴定すると きの㒕しょう物は全体がひとかたまりの餅状物であり， 粒状あるいは切片状の相分離生成物にはならない。

表 1 亿はPVAの重合度および濃度の異なる水溶洨を 濃度 $31.60 \%$ の Na $\mathrm{SO}_{4}$ 水溶液で满定し，離しょうさ廿 るのに必要な $\mathrm{Na}_{2} \mathrm{SO}_{4}$ の量を求めた結果を示した。傾向 としてPVAの浱度が低いほど，また重合度が低いはど 溶液を離しょうさせるのに必要な $\mathrm{Na}_{2} \mathrm{SO}_{4}$ の量は多い上 うであるが，おのおのの差は電解質の種類を変えた場合 の差にくらへていさい。なお重合度を変えたときの結果 は川上”の凝析力測定結果之同頑向になっている。PVA

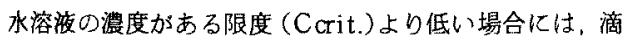
定をはじめると $\mathrm{Na}_{2} \mathrm{SO}_{4}$ 水溶液の滴下液滴のまわりに白 色矮析物が析出し，滴定がすすむにしたがってての疑析 物は擋样棒のまわりに集まる。残りの液は泡立ちがはげ しく，踓しょう物は高浱度液の場合のように全体がひと かたまりの餅状にならず，上記の擋拌棒汇付着する凝固 物と，半透明のあやあやした相分離物比分れた形で起と る。表1の*印を付した試料はこの形の離しょうを起こ した。
Table 1 Comparison of coagulation properties of various PVA solutions titrated with aqueous sodium sulfate solution.

\begin{tabular}{crlc}
\hline$P$ & $C$ & $V$ & $s$ \\
\hline 3300 & 12.44 & 1.67 & $3.45 \times 10^{-2}$ \\
& 8.91 & 1.93 & 3.99 \\
& 4.55 & 3.68 & 7.61 \\
& 2.48 & $1.86^{*}$ & 3.85 \\
\hline 1700 & 18.87 & 1.92 & 3.97 \\
& 14.83 & 2.06 & 4.26 \\
& 9.34 & 2.82 & 5.84 \\
& 4.57 & $2.71^{*}$ & 5.61 \\
\hline 500 & 29.53 & 2.60 & 5.38 \\
& 20.32 & 2.82 & 5.83 \\
& 9.82 & $3.55^{*}$ & 7.35 \\
\hline
\end{tabular}

$P$; degree of polymerization of PVA

$V$; concentration of aqueous PVA solutions in wt.\%. $C$; volume (cc) of titrated $\mathrm{Na}_{2} \mathrm{SO}_{4}$ solution $s ; \mathrm{Na}_{2} \mathrm{SO}_{4} /$ PVA solution

大柳ら 乗則にしたがいはじめる臨界分子量 $M_{c}$ は，PVAの体積 分率を $V_{2}$ とす执ば

$$
M_{c} \cdot V_{2}=4400
$$

で表わされるととを報告している。 $\bar{P}_{\mathrm{A}}=500 ， 1700$ およ び3300のPVAの分子量が臨界分子量になる上うな濃度 を求めると，それぞれ 24.5，7.5 および3.9重量パーセン トになる。表1において*印を付した実験の濃度は，上 記濃度 (Ccrit) 近傍かCcrit 以下になっている。離し ょうの際に，全体が餅状にひとつの塊りになって離しょ うするためには，PVA水溶液中の分子が十分からみ合 っているととが必要な条件の一つのように思われる。

雞しょうした餅状物を放置すると水分学放出してPVA

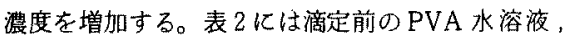

$\mathrm{Na}_{2} \mathrm{SO}_{4}$ 水溶液拉上び滴定後の離しょう物を 30 分放置 した後の鉴しょう物およびそれから放出された $\mathrm{Na}_{2} \mathrm{SO}_{4}$ を含む水の組成を示した。被滴定液であるPVA 水溶液 は，湿式紡系の際江凝固浴中を走る系状体の上うに $\mathrm{Na}_{2}$ $\mathrm{SO}_{4}$ 水溶液で囲ま机ては书らず，外部加らの脱水作用は ない。離しょうが起てるまでは被滴定試料は均一であり， 水分の遊離仙視覚では全く認められない。離しょうが起 こると $\mathrm{Na}_{2} \mathrm{SO}_{4}$ 含含む水分の避離が著しく巨視的に認め られるようなる。

表 3 には濃度 $15 \%$ の PVA 水溶波を各種電解質水溶液 を用いて，PVAが離しょうするまで滴定したときの電 解質の所要量を示した。電解質の水溶液は飽和濃度の約

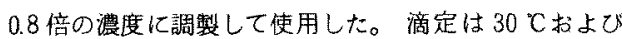
$80^{\circ} \mathrm{C}$ で実施した。表の中の $s$ の值はPVA水溶液 $1 \mathrm{~g}$ 在 凝固させるのに必要な塩の量を示しており，本報ではこ 
Table 2 An example of the composition of the component materials before and after titration

\begin{tabular}{|c|c|c|c|c|}
\hline materials & $\begin{array}{l}\text { before titr } \\
\text { PVA solutior }\end{array}$ & $\mathrm{Na}_{2} \mathrm{SO}_{4}$ solution & $\begin{array}{r}\text { after } \\
\text { coagulated } \\
\text { PVA block }\end{array}$ & $\begin{array}{l}\text { titration } \\
\text { squeezed water }\end{array}$ \\
\hline PVA & $12.27 \%$ & & $21.46 \%$ & \\
\hline $\begin{array}{l}\mathrm{Na}_{2} \mathrm{SO}_{4} \\
\text { (weight) }\end{array}$ & $(20 \mathrm{~g})$ & $\begin{array}{l}31.60 \% \\
(2.5 \mathrm{~g})\end{array}$ & $\begin{array}{r}2.494 \% \\
(15.84 \mathrm{~g})\end{array}$ & $\begin{array}{c}6.68 \% \\
(6.66 \mathrm{~g})\end{array}$ \\
\hline
\end{tabular}

Table 3 Results of titration of $15 \%$ PVA aqueous solution (20g) with various aqueous electrolyte solutions at two temperatures.

\begin{tabular}{lrccccc}
\hline temp. & \multicolumn{3}{c}{$30^{\circ} \mathrm{C}$} & \multicolumn{3}{c}{$80^{\circ} \mathrm{C}$} \\
electrolyte & $W$ & \multicolumn{1}{c}{$C$} & $s$ & $W$ & $C$ & $s$ \\
\hline$\left(\mathrm{NH}_{4}\right)_{2} \mathrm{SO}_{4}$ & 3.07 & 39.0 & $5.84 \times 10^{-3}$ & 1.98 & 43.0 & $4.25 \times 10^{-3}$ \\
$\mathrm{Na}_{2} \mathrm{SO}_{4}$ & 2.88 & 28.7 & 4.15 & 1.12 & 25.6 & 1.42 \\
$\mathrm{~K}_{2} \mathrm{SO}_{4}$ & 17.72 & 9.42 & 8.29 & 2.03 & 14.5 & 1.47 \\
$\mathrm{H}_{8} \mathrm{BO}_{3}$ & 13.25 & 5.13 & 3.54 & 1.90 & 16.0 & 1.52 \\
$\mathrm{Zn} \mathrm{SO}$ & 11.35 & 32.9 & 18.9 & 5.58 & 34.8 & 9.70 \\
$\mathrm{CuSO}_{4}$ & 12.70 & 18.0 & 11.6 & 3.41 & 30.0 & 5.08 \\
$\mathrm{Mg} \mathrm{SO}_{4}$ & 10.80 & 24.6 & 13.3 & 2.76 & 30.3 & 4.19 \\
$\mathrm{Al}_{2}\left(\mathrm{SO}_{4}\right)_{3}$ & 9.35 & 24.5 & 11.4 & 2.95 & 36.8 & 5.38 \\
\hline
\end{tabular}

$W$; titrated electrolyte solution $(\mathrm{g})$

$C$; concentration of electrolyte solution (\%)

$s$; electrolyte (g)/PVA solution (g)

の值を凝固値亡呼ぶことにする。 $s 0$ 値はホー酸 $\left(\mathrm{H}_{3} \mathrm{BO}_{3}\right)$, $\mathrm{Na}_{2} \mathrm{SO}_{4}$ ，硫酸アンモ二ウム $\left(\left(\mathrm{NH}_{4}\right)_{2} \mathrm{SO}_{4}\right)$, 硫酸カリウ $\left\llcorner\left(\mathrm{K}_{2} \mathrm{SO}_{4}\right)\right.$ の順に大きくなっている。 $s$ の值が小さい ほど凝固性は上く，との順序は長井 ${ }^{8)}$ の報告の数析力之 同傾向になっている。 $30^{\circ} \mathrm{C}$ と $80^{\circ} \mathrm{C} の$ 実験結果を比較す ると $80^{\circ}$ の場合の方が 般にポリマーの溶液に非溶剂を加えて沈測させる場合に は温度の高い之きの方が温度が低い之きより多量の非溶 剂を必要さする。本研究の場合には温度が高いはどPVA 水溶液を離しょうさせるのに必要な電解質の所要量は少 く，との離しょう現象は沈澱実験における沈没見象とは 異なるようである。

つぎに，凝固存局所的な分子運動生の面加ら検討する ために，高分解能NMRによる実験を行なった。この場 合，PVA水溶液に排歪分子のプロトンの寄与を除 去するために，PVA重水溶液を用いた。との重水溶液 を用いても，電解質を用いた離しょう実験において，を の結果は水溶液を用いた場合と大きな差は認められなか っだしたかっってPVA重水溶液もその物理的性質は PVA水溶液と変わらないことが予想される。

図1には，灃度 $15 \%$ \% PVA重水溶液 (1), (1)を7 7 で 13 日間放置してケ゚ル化させた試料(2)，(1)に $\mathrm{Na}_{2} \mathrm{SO}_{4} の$ 重水溶泎を加えて離しょうさせた試料(3)のプロトンNMR
スペクトルのメチンおよびメチレン 基のプロトンの吸収を示した。表 4 にはおのおのの吸収の半值愊を示し た。図 1 およひ表 4 をみると，(1)， (2)にははとんじ差がなく，(3)はよ り半值幅が大きくなっている。低温 放置でゲル化させた試料は，試料が ゲル化して流動性を失っているにも かかわらず，メチン、メチレン基の 運動性はゲル化していない試料とお まり変わらず， $\mathrm{Na}_{2} \mathrm{SO}_{4}$ で疑固させ た試料では，てれらの基の運動生が 小さくなっているといえる。

以上の結果から次の上うなととか 考えられる。線幅か汒かる原因には いろいろあるが，本実験の場合は期 定条件および試料の状態から同所的 な分子の運動性が主原因になってい ると考えられる。試料(2)では巨視的 には流動狌を失っているが，局所的 な分子運動性は(1)の場合之大差がな く，(2)では温度をあげれば巨視的な<smiles>CC(C)(C)CC(O)CC(C)(C)C</smiles>

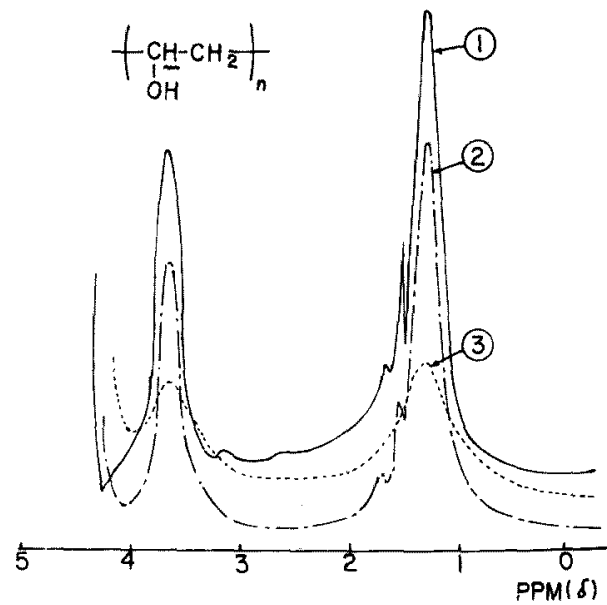

Fig. $1{ }^{1} \mathrm{H}$-NMR spectra of PVA solutions

1 PVA deutrium oxide solution

2 PVA deutrium oxide solution left for standing at $7 \mathrm{C}$ for 13 days.

3 PVA deutrium oxide solution coagulated by an addition of $\mathrm{Na}_{2} \mathrm{SO}_{4}$ deutrium oxide solution. 
Table 4 Half height width of NMR absorption for $\mathrm{CH}$ and $\mathrm{CH}_{2}$ for various state of PVA solutions.

\begin{tabular}{lcc}
\hline & $\begin{array}{c}\text { Half height width } \mathrm{H}_{\frac{1}{8}}(\mathrm{~Hz}) \\
\mathrm{CH}\end{array}$ & \multicolumn{1}{c}{$\mathrm{CH}_{2}{ }^{2}$} \\
\hline PVA solution & $7.5 \times 3$ & $8.0 \times 3$ \\
PVA solution left for standing & $7.5 \times 3$ & $7.8 \times 3$ \\
at $7 \mathrm{C}$ for 13 days. & $12.0 \times 3$ & $14.5 \times 3$ \\
\hline PVA solution coagulated by $\mathrm{NaOH}$ &
\end{tabular}

$25^{\circ}$ Cで放置すれば短時間て離しょうするて と在確加ている。以後時間の経過化伴う 動的粘弹性の変化を測定した。困2 亿は綐 軸に損失コンプライアンス $\left(J^{\prime}\right)$ ，横朝に放 置時間をとって両対数プロットで示した。 $10^{\circ} \mathrm{C}$ では 24 時間放置しても離しょうしな かった。その後試料を1/分の速度で昇温 したととろ温度が $60^{\circ}$ Cを越え，J”の值か
流動性を回復するととから，分子間を束縛する力は弱 あのと思われる。一万(3)で離しょうが起こった場合には， 表 2 にみられるように脱水による局所的な濃度上昇上， それに伴なう分子間相互作用の增大に上って，局所的な 分子運動性すかなりおさえられていることを示している と考えられる。

凝固に関連するPVA分子の運動性についてさらに粘 弾性測定のデータを用いて考察を行なった。濃度 $15 \%$ の PVA水溶液に $\mathrm{Na}_{2} \mathrm{SO}_{4}$ 水溶液を離しょう前，まだ液加 半透明な状態のときまで滴定し，滴定後の試料をすばや くねじれ振り子型レオォーターのcupに入れ，bobを取 付けて $10^{\circ}$ Cに急冷した。この試料は泠却せずにそのまま

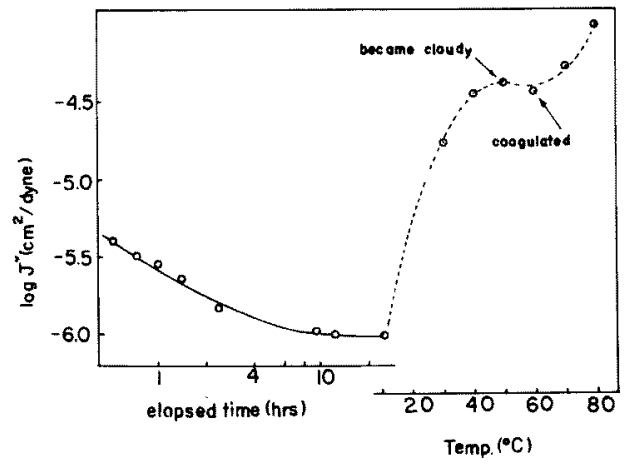

Fig. 2 Loss compliance of the mixture of PVA and $\mathrm{Na}_{2} \mathrm{SO}_{4}$ aqueous solution plotted against elapsed time for gellation and temperature elevated after the gellation.
$10^{-5} \mathrm{~cm}^{2} /$ dyneを上回る值になって試料は離しょうを起こ した。その際の温度に対するJ゙の変化図 2 の右側の部 分に示した。ゲル化させた試料はJ゙の大きさから考えて 6流動性は示さず，また変形させて6回復性の変形が起 こると考えられる。ゲル化させれば24時間経過しても離 しょうは起こらなかったこと，温度を上げてゲルが瀜解 するような状態にすれば離しょうが起こったととは，こ の現象にPVAの分子運動性が関与しているととを示すと 考えられる。試料が $\mathrm{Na}_{2} \mathrm{SO}_{4}$ を含んでいるのにゲル化を させると離しょうが起とらなかったてとから考えて，離 しょうが起こるためにはPVA分子がある大きさ以上の 易動性をもっていることが必要と考えられる。表 いて $80^{\circ} \mathrm{C}$ 方加 $30^{\circ} \mathrm{C}$ 場合よりもPVA水溶液を離しょ うさせるのに必要な $\mathrm{Na}_{2} \mathrm{SO}_{4}$ の量が少なくて上い理由の 一つにPVAの多子運動性加凝固現象に関与しているとと を挙げるとよができる。

\section{文献}

1）大杉鉄郎；「ポリビニルアルコール」(桜田一郎編) 高分子学会, p.442.(1956)

2) 中保治郎; 高分子化学, 27, 797 (1970)

3）友成九十九，大杉鉄郎，宮崎貞丸，須田輝夫，由辺 健一(确敷レイヨン)；特公，昭 31-2370

4）川上博；「合成纎維ビニロンに関する研究」高分 子化学協会, p.47. (1949)

5) Y. Oyanagi, M. Matsumoto; J. Colloid Sci., 17, 426 (1962)

6) 長井栄一; 日本化学繊維研究所講演集， 5, 5(1940) 